\title{
Lung Cancer following Bronchoscopic Lung Volume Reduction for Severe Emphysema: A Case and Its Management
}

\author{
Celine Tummino $^{a}$ Fabien Maldonado $^{c}$ Sophie Laroumagne ${ }^{b}$ Philippe Astoul ${ }^{b}$ \\ Hervé Dutau ${ }^{\mathrm{b}}$ \\ ${ }^{a}$ Department of Pulmonology and Allergology, and ${ }^{b}$ Department of Thoracic Oncology, Pleural Disease and \\ Interventional Pulmonology, North University Hospital, Marseille, France; ' Division of Pulmonary and Critical Care \\ Medicine, Mayo Clinic, Rochester, Minn., USA
}

\section{Established Facts}

- Bronchoscopic lung volume reduction has been proposed as a potentially safer alternative to surgery in selected cases of patients suffering from severe emphysema.

- Complications of this technique do occur and include pneumothoraces, pneumonia, COPD exacerbations, hemoptysis, and valve migrations.

\section{Novel Insights}

- Lung cancer can be an associated condition following bronchoscopic lung volume reduction, which is due to the fact that lung cancer is highly prevalent in COPD/emphysema.

- Diagnosis of lung cancer can be challenging when it occurs behind the valves, especially in the case of postvalve atelectasis where it can be missed or delayed.

\section{Key Words}

COPD · Emphysema $\cdot$ Lung cancer $\cdot$ Bronchoscopic lung volume reduction $\cdot$ Surgical lung volume reduction

\footnotetext{
Abstract

Bronchoscopic lung volume reduction using endobronchial valves has been suggested as a potentially safer alternative to surgery in selected cases. Complications of this technique include pneumothoraces, pneumonia, COPD exacerbations, hemoptysis, and valve migrations. We report the case of a
}

male patient who developed a parenchymal mass in the treated lobe after valve insertion. Due to severe emphysema, transthoracic needle aspiration was not feasible. Removal of the valves was mandatory to perform transbronchialbiopsies which revealed a non-small cell primary lung cancer. This first description illustrates the potential risk of lung cancer development following bronchoscopic lung volume reduction and highlights the different approach to diagnosis and management of indeterminate peripheral lung lesions needed in this context.

Copyright $\odot 2011$ S. Karger AG, Basel

\section{KARGER}

Fax +4161306 1234

E-Mail karger@karger.ch

www.karger.com
(C) $2011 \mathrm{~S}$. Karger AG, Basel

$0025-7931 / 12 / 0835-0418 \$ 38.00 / 0$

Accessible online at:

www.karger.com/res
Dr. Hervé Dutau

Department of Thoracic Oncology, Pleural Disease and Interventional Pulmonology North University Hospital

Chemin des Bourrely, FR-13015 Marseille (France)

Tel. +33 491965 971, E-Mail herve.dutau@ mail.ap-hm.fr 


\section{Introduction}

Bronchoscopic lung volume reduction (BLVR) using one-way valves, has been proposed as a potentially safer alternative to surgery in selected patients with severe emphysema, with reported lower morbidity and mortality. Complications do, however, occur and include COPD exacerbations, pneumonia, valve migrations, hemoptysis, and pneumothoraces. In this case report, we describe the case of a patient who developed a lung carcinoma in the treated lobe and its management.

\section{Case Report}

A 69-year-old male patient was referred 5 years ago to our tertiary care center for screening and possible inclusion in the VENT trial [1] assessing BLVR via unidirectional endobronchial one-way valves. His past medical history was essentially significant for severe COPD (stage III of the GOLD classification). He was a former smoker (60 pack-years). The patient's respiratory function remained significantly altered despite optimal medical treatment combining inhaled bronchodilators and steroids, long-term oxygen therapy, and pulmonary rehabilitation. Chronic productive cough and severe dyspnea on exertion were his main symptoms. Lung function studies revealed nonreversible severe obstruction $\left[\mathrm{FEV}_{1}=1.15\right.$ liters ( $36 \%$ of predicted) $]$ and significant hyperinflation ( $R V=170 \%$ of predicted, TLC $=115 \%$ of predicted). Arterial blood gases analysis demonstrated hypoxemia $\left(\mathrm{PaO}_{2}=59 \mathrm{~mm} \mathrm{Hg}\right)$ without hypercapnia $\left(\mathrm{PCO}_{2}=36 \mathrm{~mm}\right.$ $\mathrm{Hg}$ ). The 6-min walk test was $330 \mathrm{~m}$ with desaturation to $90 \%$. Computed tomography (CT) of the chest revealed severe heterogenous emphysema with a marked predominance in the lower lobes (fig. 1). The patient, eligible based on inclusion and exclusion criteria, was therefore enrolled in the VENT study with the left lower lobe as the target for lung volume reduction. Two oneway valves were implanted in the left lower lobe (one small valve for $\mathrm{B} 6$ and a larger one for the remaining segmental bronchi). The subjective clinical benefit after valve insertion was very moderate and no significant changes were identified either on lung function studies or on the 6-min walk test. The absence of clinical improvement was associated with the absence of left lower lobe atelectasis. This was explained by collateral ventilation between the upper and lower lobes as suggested by the presence of an incomplete interlobar fissure on CT. One year later, the patient developed a mass in the left lower lobe detected after a surveillance CT scan (fig. 2). The patient was asymptomatic and the new lesion was incidentally identified. Hence, bronchoscopy with transbronchial biopsies was recommended. Suspected etiologies were partial atelectasis, infection, or tumor. Transthoracic needle aspiration was deemed too dangerous because of a high risk of pneumothorax. Valve removal was then performed and no evidence of macroscopic malignancy was noticed. Transbronchial biopsies under fluoroscopic guidance were then performed. Pathologic examination was consistent with squamous cell carcinoma. The disease was staged T2N0M0. Oncologic treatment was limited to chemotherapy. Radiotherapy was not considered

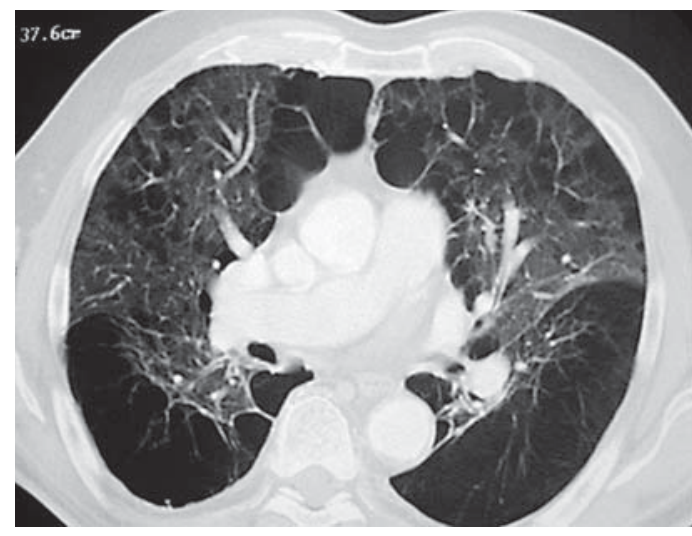

Fig. 1. CT scan slide before placement of the valves: heterogeneous emphysema predominantly affecting the lower lobes.

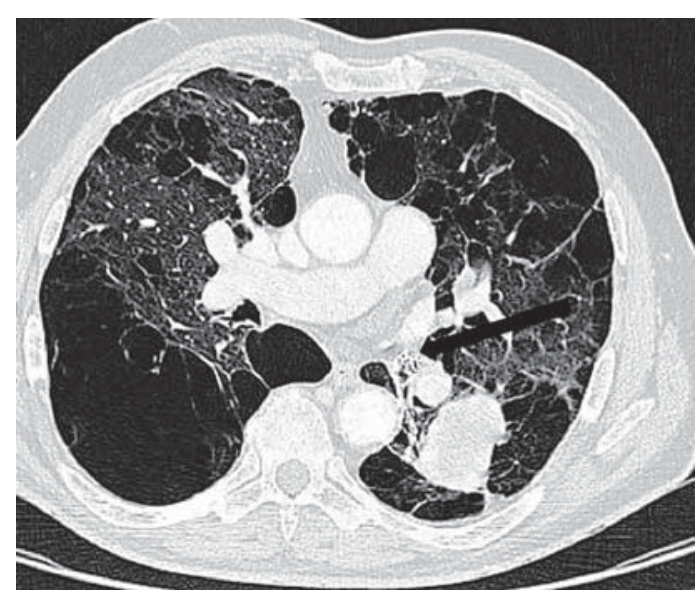

Fig. 2. Parenchymal mass beyond the valves (black arrow) in the left lower lobe.

a reasonable option due to the patient's altered lung function. Unfortunately, the patient died from septicemia secondary to severe leukopenia as a complication of chemotherapy 2 months after its onset.

\section{Discussion}

BLVR via endobronchial valves has been suggested as a potential alternative to surgical lung volume reduction, with a better safety profile [2]. This technique has been shown to be feasible and is well tolerated, with reduced morbidity and mortality compared to its surgical counterpart [3-7]. Initial encouraging results from small studies on BLVR have suggested an improvement in quality of 
life, pulmonary function with improvements in flows and reduction in air trapping, and the 6-min walk test [3-6]. Described complications of BLVR include pneumothorax, granulation tissue, respiratory infections, valve migration, and unsuccessful atelectasis due to poor positioning of the valves or collateral ventilation [3-8].

The VENT study was the first prospective multicenter randomized controlled trial evaluating the efficacy of BLVR compared to optimal medical treatment in patients with heterogeneous emphysema [1]. The results of this study were somewhat disappointing in that although statistically significant, the modest improvements in lung function, exercise tolerance, and symptoms were of unclear clinical significance and occurred at the cost of more frequent COPD exacerbations, respiratory infections, and hemoptysis [1].

The efficacy of BLVR may have been obscured by a heterogenous population of patients included in the study. Two conditions are required for BLVR to be effective: a marked heterogeneity between lobes and complete interlobar fissures that preclude collateral ventilation, which prevents atelectasis and, therefore, lung volume reduction. Further studies are needed to confirm that the subset of patients satisfying these conditions may benefit clinically from BLVR [1].

In our case, the fact that BLVR was unsuccessful ultimately allowed for the prompt identification of a malignant lesion which would likely have been missed in the case of postvalve atelectasis.
Post-BLVR lung cancer might be even more difficult to detect after treatment with either bronchoscopic thermal vapor ablation [9] or biological lung volume reduction [10] due to the very intense inflammatory tissue reaction observed with these treatments.

We believe this case to be an important addition to the current literature as it illustrates the potential diagnostic difficulties that may arise in 'directed atelectasis' via BLVR.

Smoking is the main risk factor for both lung cancer and emphysema. The incidence of lung cancer in patients with emphysema is estimated at 17/1,000 per year [11]. Interestingly, both radiographic emphysema and, to a lesser extent, airflow obstruction appear to be risk factors for lung cancer independently of smoking history [11]. This highlights the high risk of developing lung cancer in patients who are candidates for BLVR.

In summary, our case highlights the risk of missing the development of lung cancer in atelectatic regions in patients treated via BLVR. This issue is of great importance and should be discussed with patients before consideration of endobronchial treatment for emphysema.

\section{Disclosure Statement}

The authors have no conflicts of interest.

\section{References}

1 Sciurba FC, Ernst A, Herth FJ, Strange C, Criner GJ, Marquette CH, Kovitz KL, Chiacchierini RP, Goldin J, McLennan G, VENT Study Research Group: A randomized study of endobronchial valves for advanced emphysema. N Engl J Med 2010;363: 1233-1244

2 Ramsey SD, Berry K, Etzioni R, Kaplan RM, Sullivan SD, Wood DE, National Emphysema Treatment Trial Research Group: Cost effectiveness of lung-volume-reduction surgery for patients with severe emphysema. N Engl J Med 2003;22:2092-2102.

-3 Toma TP, Hopkinson NS, Hillier J, Hansell DM, Morgan C, Goldstraw PG, Polkey MI, Geddes DM: Bronchoscopic volume reduction with valve implants in patients with severe emphysema. Lancet 2003;15:931-933.

4 Yim, A.P, Hwong TM, Lee TW, Li WW, Lam S, Yeung TK, Hui DS, Ko FW, Sihoe AD, Thung KH, Arifi AA: Early results of endoscopic lung volume reduction for emphyse- ma. J Thorac Cardiovasc Surg 2004;127: 1564-1573.

5 Venuta, F, de Giacomo T, Rendina EA, Ciccone AM, Diso D, Perrone A, Parola D, Anile M, Coloni GF: Bronchoscopic lung-volume reduction with one-way valves in patients with heterogenous emphysema. Ann Thorac Surg 2005;79:411-417.

6 Wan IY, Toma TP, Geddes DM, Snell G, Williams T, Venuta F, Yim AP: Bronchoscopic lung volume reduction for end-stage emphysema: report on the first 98 patients. Chest 2006;129:518-526.

7 Venuta F, Rendina EA, De Giacomo T, Anile M, Diso D, Andreetti C, Pugliese F, Coloni GF: Bronchoscopic procedures for emphysema treatment. Eur J Cardiothorac Surg 2006;29:281-287.

8 Sterman DH, Mehta AC, Wood DE, Mathur PN, McKenna RJ Jr, Ost DE, Truwit JD, Diaz P, Wahidi MM, Cerfolio R, Maxfield R, Musani AI, Gildea T, Sheski F, Machuzak M,
Haas AR, Gonzalez HX, Springmeyer SC, IBV Valve US Pilot Trial Research Team: A multicenter pilot study of a bronchial valve for the treatment of severe emphysema. Respiration 2010;79:222-233.

-9 Snell GI, Hopkins P, Westall G, Holsworth L, Carle A, Williams TJ: A feasibility and safety study of bronchoscopic thermal vapor ablation: a novel emphysema therapy. Ann Thorac Surg 2009;88:1993-1998.

10 Reilly J, Washko G, Pinto-Plata V, Velez E, Kenney L, Berger R, Celli B: Biological lung volume reduction: a new bronchoscopic therapy for advanced emphysema. Chest 2007;131:1108-1113.

11 de Torres JP, Marín JM, Casanova C, Cote C, Carrizo S, Cordoba-Lanus E, Baz-Dávila R, Zulueta JJ, Aguirre-Jaime A, Saetta M, Cosio MG, Celli BR: Lung cancer in patients with COPD: incidence and predicting factors. Am J Respir Crit Care Med 2011, E-pub ahead of print. 